\title{
Processos de singularização no modo psicossocial
}

\section{1 Carmen Terezinha Argiles, ${ }^{2}$ Luciane Prado Kantorski, \\ ${ }^{3}$ Janaína Quinzen Willrich, ${ }^{4}$ Valéria Christello Coimbra I}

Resumo: O artigo objetiva relacionar as possibilidades de produção de subjetividade singularizada no serviço de CAPS de AlegreteRS, entendendo-se a necessidade de identificar as aproximações e distanciamentos das práticas desenvolvidas e dos objetivos propostos a partir da reforma psiquiátrica nesse serviço. Utilizou-se a modalidade de estudo de caso com abordagem qualitativa descritiva e analítica. Foram efetuadas entrevistas semiestruturadas com 11 usuários e 21 trabalhadores e observação participante, perfazendo um total de 253 horas. Encontraram-se nos espaços do serviço aspectos de inovação nas práticas e dinâmicas propostas para pensar, criar e resistir, potencializando a subjetivação e os processos de singularização das pessoas envolvidas na atenção psicossocial. As relações construídas mobilizam para o desenvolvimento de múltiplos recursos individuais, coletivos e sociais para um modo singular de viver em sociedade, com respeito às diferenças, aos desejos, aos modos de relação e de concepção de mundo.

> Palavras-chave: saúde mental; atenção psicossocial; subjetividade; processos de singularização.

\footnotetext{
1 Centro de Atenção Psicossocial do Fragata da Prefeitura Municipal de Pelotas. PelotasRS, Brasil (carmen_argiles@ yahoo.com.br).

${ }^{2}$ Faculdade de Enfermagem da Universidade Federal de Pelotas. Pelotas-RS, Brasil (kantorski@ uol.com.br).

${ }^{3}$ Faculdade de Enfermagem da Universidade Federal de Pelotas. Pelotas-RS, Brasil (janainaqwill@yahoo.com.br).

${ }^{4}$ Faculdade de Enfermagem da Universidade Federal de Pelotas. Pelotas-RS, Brasil (valeria. coimbra@gmail.com).
}

Recebido em: 13/10/2015 Aprovado em: 14/07/2016 


\section{Introdução}

Este estudo ${ }^{1}$ busca pensar as mudanças previstas a partir da reforma psiquiátrica brasileira para os serviços substitutivos à estrutura manicomial no país. Essas mudanças referem-se ao modo de promover o cuidado e, em especial, à possibilidade de os Centros de Atenção Psicossocial trabalharem com a perspectiva da produção de subjetividade singularizada de seus usuários.

O movimento de reforma psiquiátrica brasileira propõe a desconstrução do equipamento manicomial, não somente em relação aos espaços físicos de contenção e aprisionamento dos corpos, explícitos na situação de internação, mas também no que diz respeito à desmontagem de toda a organização psiquiátrica tradicional, que parte da concepção de doença mental como conjunto de incapacidades para a vida em sociedade (AMARANTE, 1996).

Com a aprovação da Lei $n^{\circ} 10216 / 01$, o processo de reforma psiquiátrica ganha impulso no Brasil após mais de uma década de luta. Diversas portarias propõem a construção da rede de atenção à saúde mental com benefícios, por exemplo, como o programa "De volta para casa", gestão e fiscalização do processo de redução de leitos nos hospitais psiquiátricos (BRASIL, 2005). Apesar de inúmeras dificuldades, o ideário de um cuidado psiquiátrico para além dos muros das instituiçōes manicomiais passa a ser concretizado. A expansão de serviços de CAPS no Brasil ultrapassa 1650 serviços implantados com financiamento da União e iniciativa das gestões municipais (BRASIL, 2011).

Tendo em vista a existência desses serviços há mais de uma década, este estudo parte da necessidade de analisar os serviços de CAPS que focalizam a possibilidade de produção de subjetividade. Essas práticas são presentes nos processos de trabalho instituídos nos CAPS em contraposição ao modo manicomial de cuidar, com proposta centrada na doença, na contenção do sujeito e na experiência da loucura.

$\mathrm{O}$ fato de conhecermos como os serviços operam permite-nos identificar aspectos de aproximação e distanciamento em relação aos objetivos mais amplos do movimento de reforma. Além disso, possibilita-nos instaurar práticas de cuidado produtoras de significado e sentido, com vistas a operar mudança de realidades no que se refere à centralidade que a doença ocupa na vida das pessoas. A exclusão, o estigma, a tutela, por exemplo são realidades que comprometem as possibilidades de vida independente e de cidadania. $\mathrm{O}$ 
desafio do modo psicossocial para produzir singularidades e subjetividades na contramão do modo manicomial, que produzia subjetividades serializadas e disciplinadas (COSTA-ROSA, 2006), relaciona-se, intrinsecamente, ao modo de trabalho institucional e às práticas por esse produzidas.

O conceito subjetividade adotado neste estudo não trata daquela construída pelo pensamento cartesiano, individual, ego-centrada, restrita ao sujeito, como consciência individual. Também não se refere à subjetividade descrita pela Psicologia a partir do final do século XIX, focada no indivíduo como dotado de uma subjetividade substancial, relacionada ao núcleo íntimo de cada pessoa. Entendemos a subjetividade como prática, que se constitui a partir de sujeitos práticos. Em outros termos, trata-se de uma subjetividade material, produzida pelos sentidos, imanente, porque se dá no mundo em relação com as coisas que dele fazem parte, sendo, também, relacional, associativa e interacionista (SOARES; MIRANDA, 2009).

Desse modo, entendemos a subjetividade com características individuais, vivida e assumida por indivíduos em sua existência particular, resultante de determinações coletivas de origens diversas: econômicas, midiáticas, tecnológicas, dentre outras. Essa subjetividade processual e agenciada encontra, certamente, o corpo individual; e, mesmo não aderindo à representação do indivíduo, existem momentos em que a subjetividade se reconhece num corpo individual, num modo de individuação (GUATTARI; ROLNIK,2011).

Consideramos, assim, que a produção da subjetividade passa pela concepção da criação, de modelização e fabricação; encontra-se em processo de transformação a partir de interaçôes de naturezas diversas com as máquinas sociais. Os dispositivos de produção de subjetividade podem ser de escala coletiva, social ou de escala molecular e microfísica, no sentido descrito por Foucault (1992), com ações sobre a vida cotidiana.

Este estudo utilizará o conceito de subjetividade que envolve tudo aquilo que concorre para a produção de um em "si", um modo de existir, um estilo de existência, fluido, dinâmico, que possibilite a produção de singularidades (SOARES; MIRANDA, 2009).

A produção de singularidade é um processo dinâmico que possibilita movimentos para a construção de territórios existenciais, expandindo a perspectiva de vida para além das determinações da subjetividade homogeneizante, de 
ordem capitalística. Para compreender a produção de subjetividade nos serviços de saúde mental, delimitam-se como categorias de análise os processos de singularização, os deslocamentos, a heterogeneidade, que concorrem para a produção de subjetividade singularizada. Guattari (2011) argumenta que os trabalhadores da área social, tais como os profissionais dos CAPS, atuam de certo modo na produção de subjetividades, vindo a operar para a reprodução de subjetividades capitalísticas ou agenciando e potencializando micropolíticas processuais e criativas. Assim, este artigo se coloca como um recurso para acionar o pensamento desses trabalhadores. Desse modo, o objetivo deste trabalho é relacionar as possibilidades de produção de subjetividade singularizada nos espaços do Centro de Atenção Psicossocial de Alegrete-RS, e a operacionalização das práticas e princípios da reforma psiquiátrica.

\section{Metodologia}

Este artigo apresenta dados de um subprojeto da pesquisa de avaliação de CAPS da região sul do Brasil - CAPSUL II, realizada em 2011. O projeto de pesquisa foi aprovado pelo Comitê de Ética da Faculdade de Medicina da Universidade Federal de Pelotas sob o parecer de no 017/11. A pesquisa foi financiada pelo Ministério da Ciência e Tecnologia através do CNPq em parceria com o Ministério da Saúde.

A pesquisa CAPSUL II caracteriza-se como reavaliação, sendo a primeira edição da pesquisa - CAPSUL - realizada em 2006, nos estados do Rio Grande do Sul, Santa Catarina e Paraná. Essa edição investigou aspectos de estrutura, processo de trabalho e resultados dos CAPS, ouvindo usuários, familiares, trabalhadores e coordenadores dos serviços nos três estados, por meio de um estudo qualitativo e quantitativo (KANTORSKI, 2006).

$\mathrm{Na}$ etapa de avaliação qualitativa, o CAPSUL II propôs três estudos de caso, incluindo os municípios de Alegrete/RS, Foz do Iguaçu-PR e Joinville-SC. O presente artigo apresentará os dados do estudo do caso do município de Alegrete/ RS, com uma abordagem qualitativa descritiva e analítica, tipo estudo de caso. Optou-se por esse município pelas seguintes razões: (1) o serviço ali realizado é o mais antigo dentre os três municípios selecionados; (2) o município construiu uma história significativa de avanços em relação à constituição de uma rede consistente de atenção em saúde mental (CAPS II, CAPS I, CAPS AD, SRT, 
rodas de saber, leitos em hospitais gerais, referência regional, entre outras

atividades inovadoras); e (3) houve movimentos em relação à garantia dos pressupostos da reforma psiquiátrica em sua experiência de atenção psicossocial.

O estudo, requisito para a realização do mestrado acadêmico em Enfermagem, empregou a metodologia de avaliação de quarta geração, construtivista e responsiva de Guba e Lincoln $(1985$; 1989) e adaptada por Wetzel (2005). A fim de obter uma abordagem mais ampla da realidade, optou-se pela modalidade de estudo de caso. Os dados que constituem esta pesquisa foram coletados entre os meses de junho e agosto de 2011 por meio de entrevistas semiestruturadas com 11 usuários e 21 trabalhadores. Além desses, integram os dados da pesquisa resultados de observação participante. Os dados perfazem um total de 253 horas.

Os sujeitos deste estudo serão desidentificados, de maneira a preservar o anonimato de suas identidades, sendo codificados pela letra correspondente ao seu grupo de interesse - U (usuários) ou T (trabalhadores) - seguida da ordem em que foram entrevistados.

\section{Resultados e discussão}

Considerando toda a gama de importantes proposiçóes de mudanças que compõem o ideário da reforma psiquiátrica, uma das mais inquietantes questões para pensar a produção de subjetividade no âmbito dos serviços de saúde mental diz respeito às possibilidades que se abrem à reconstituição de projetos de vida, à retomada de direitos, de desejos, de modos de ser e estar no mundo, de acessos, de relações. Diz respeito, enfim, a tudo o que nos constitui enquanto alguém em sua singularidade, sem pensarmos, contudo, que estamos à parte do mundo social, sistêmico, organizado, institucionalizado e globalizado.

O desafio que se coloca para esses locais de cuidado éo de serem suficientemente abertos, disparadores de processos de expansão individual e coletiva e ao mesmo tempo continentes em relação ao sofrimento. Essas instituições de trabalho e cuidado precisam conservar certa estrutura de modo a fornecerem um contorno ou uma conformação ao usuário e ao trabalhador.

Ao questionarmos a possibilidade de os serviços de CAPS corresponderem atualmente ao ideário do modo psicossocial, construído no bojo das proposiçôes do movimento de reforma psiquiátrica, pensamos poder traçar a condição 
desses locais para promover, possibilitar ou disparar processos de subjetivação individual e coletiva. Para tanto, focalizamos as pessoas - usuários e trabalhadores - em suas relaçôes interpessoais no âmbito da instituição e fora dela, em seu entorno pessoal, social, individual e coletivo, bem como as formas de funcionamento institucional, em suas relações e implicações.

\section{Os processos de singularização}

Os processos de singularização ocorrem, segundo Guattari (2011), quando se associam, aglomeram, emprestam dimensões de diversas espécies, não estando, necessariamente, relacionados a processos de individuação ou a uma identidade individual. Um processo de singularização é caracterizado por ser automodelador, por possibilitar a construção de seus próprios referenciais, teóricos ou práticos, ao entrar em contato com as diferentes situações. Esse processo não deve, contudo, permanecer dependente de poderes dos mais diversos níveis, como econômicos, técnicos, de campos de saberes ou outros. Considerando a produção de subjetividade como uma linha de montagem, na qual esta se coloca como mais um produto, a possibilidade de configurar-se de forma não serial ou massificada, partindo de referenciais próprios e autônomos, apresenta-se como possibilidade de singularização.

$\mathrm{O}$ modo como os indivíduos vivem essa subjetividade oscila entre dois extremos: uma relação de alienação e opressão, na qual o indivíduo se submete à subjetividade tal como a recebe, ou uma relação de expressão e criação, na qual o indivíduo se reapropria dos componentes da subjetividade, produzindo um processo que Guattari chamaria de singularização (GUATTARI, 2011, p. 42).

O exercício de um controle social realizado através de produção de subjetividades massificadas pelo sistema de globalização contrapõe-se aos focos de resistência, como os processos de diferenciação permanente, que Guattari (2011) denomina "revolução molecular" e que nada mais são do que processos de singularização. Aspecto da produção de subjetividade, do qual nos aproximamos e exploramos neste artigo.

Nas falas de usuários no CAPS encontram-se processos de resistência e singularização como os transcritos abaixo:

Aí eu não concordo, tanto que eu não participo de várias oficinas, de nenhuma, quase [U1]. 
É a conduta política dos trabalhadores de saúde mental [...], as pessoas não gostam

de gente que tem pensamento autônomo [...] enfim a gente sustenta o movimento com o grupo que tem pensamento autônomo [T3].

É uma equipe que começou com a reforma defendendo um projeto que era contra-hegemônico, a sociedade não queria muito, mas não tinha muita opinião sobre isso, mas o modelo instituído no município não era favorável e a equipe toda bancou e mostrou que era possível [T4].

A possibilidade de discordar e manter-se alheio, nesse caso, a situações do cotidiano que parecem corresponder ao adequado porque partem de uma proposta terapêutica construída de forma a incluir os usuários em novas experiências, coloca-se de forma individual e coletiva como uma resistência no sentido de se singularizar. Horkheimer (2007) assevera que o núcleo da verdadeira singularidade é a resistência, que surge entre as pessoas comuns e anônimas na multidão.

As pessoas com história de internações psiquiátricas e vivências de exclusão social, marcadas pelo estigma da loucura, perderam a voz e o espaço de expressão, estando relegadas ao esquecimento e à situação de objetivação pela sociedade. Nesse contexto, as falas que representam oposição ou resistência relacionam-se ao conceito proposto por Deleuze (1988) e Deleuze e Guattari (1996) de resistir, no sentido de criação. Quando é possível a expressão de discordância e de posicionamento próprio, cria-se um outro lugar subjetivo na existência individual e coletiva.

As propostas que procuram promover espaços diferenciados e, por isso, menos serializados, no âmbito da instituição podem colocar-se como uma armadilha que retém a criatividade e limita agenciamentos quando não correspondem a interesses e desejos dos envolvidos. Os agenciamentos são compreendidos como um conjunto de relações materiais e um regime de signos que lhe correspondem. Os agenciamentos de enunciação são formados por meios de expressão, representações, comunicações e pelo seu conteúdo; os agenciamentos maquínicos, estes são povoados de devires e de intensidades, de circulações intensivas, de multiplicidades. Trata-se de uma correlação entre duas faces: a do agenciamento de enunciação e a do agenciamento maquínico (GUATTARI; ROLNIK, 2011).

Ao oportunizar os espaços de expressão e criação, o serviço de saúde mental coloca-se potente para revoluções moleculares, ainda que de ordem infra ou 
interpessoal, mas que representam linhas de escape à subjetividade produzida pelo sistema dominante. Pode-se entender esses movimentos como linhas de fuga, que produzem rupturas com sistemas de dominação, de serialização e de homogeneização, e estabelecem processos que podem caracterizar o que Guattari e Rolnik (2011) chamaram de revoluçooes moleculares ou singularização. Esses processos ocorrem quando há possibilidade de criação de seus próprios sistemas de referências a partir de processos de autonomia, de diferenciação, de modos de relacionar-se e constituir seus espaços de vida. Implicam operar seu próprio trabalho de semiotização da realidade.

(O CAPS) ajuda, ajuda porque as pessoas que vêm aqui, porque a gente mesmo fala para as pessoas, não é assim que vocês devem nos tratar, nós somos gente como vocês, nós somos pessoas, seres humanos, como diz o outro, e nós queremos ser bem tratados para quando vocês foram lá no CAPS tratar bem vocês [U8].

Que a gente entende que é o que nos norteia, a gente tem que trabalhar de acordo com as necessidades das pessoas e não querer enquadrar as pessoas [T3].

Que eu acho que é isso que a sociedade tem que deixar [...] de ser egoísta e abraçar as ideias das outras pessoas por mais que não seja a sua, é que o ser humano tem esse costume de não querer abraçar uma ideia, por mais que ela seja boa, quando é de outra pessoa [U1].

As questôes colocadas na fala seguinte trazem aquilo que podemos entender como próprio da diferença, que é justamente um feixe de multiplicidades, formas de representar, através de variáveis possíveis na sociedade, opondo-se à demanda desta pela uniformização. Essas multiplicidades circunscrevem um campo de relações heterogêneas, de devires, linhas de fuga, agenciamentos e desterritorializaçôes. $\mathrm{O}$ usuário entende o espaço institucional como um espaço em que as possibilidades de existência deveriam ser de variação e singularização, deixando de procurar o inverso, isto é, a adaptação como possibilidade de alcançar pertencimento nessa sociedade.

A produção subjetiva opera por agenciamentos e implica deslocar-se do que é representacional, do uno, identitário e totalizante. Esta se encontra na singularização, na diferença e no movimento rizomático que constitui redes conectivas, heterogêneas e de variação, produzindo a existência em uma processualidade de devir subjetivo.

Existir é diferir, reafirma Pelbart (2003), entendendo a diferença como substancial, o que ela tem de mais próprio e mais comum. O autor coloca ainda a invenção como diferença introduzida no mundo na direção da resistência. 
A gente trabalha muito com alternativas que não necessariamente são instituídas, elas são instituídas para aquele caso e isso é muito complexo, muito complexo porque tu vai ter um monte de proposta terapêutica e cada uma diferente da outra [...] é como se a gente estivesse trabalhando artesanalmente [T4].

A instituição oferece espaços para o acontecimento de deixar-se afetar, produz devires que podem ir ou não ao encontro do esperado, quando abre canais para o inesperado, inclusive para a loucura. O propósito de anular ou evitar sensibilidades para assim estabelecer melhor o controle individual e coletivo faz parte do sistema institucional. Porém, esses serviços colocam-se, teoricamente, como terreno de escape, favorecendo processos de vivências singulares e de rupturas com lugares pré-estabelecidos, tais como o lugar estigmatizado socialmente para a loucura. Nas falas a seguir é possível encontrar críticas a esses aspectos, produzidas por usuários e trabalhadores do serviço estudado.

Como muitas vezes a gente não é amado, muitas vezes a gente não tem o amor, assim, que a gente espera, não é? Sai um, dá uma pedrada, sai outro e diz uma palavra e diz outra, então a gente tenta sim se colocar melhor possível, e eu tenho enfrentado [...] só levando com remédio porque assim na cabeça às vezes não, a mente da gente fecha, sabe, e não tem uma palavra pra dizer e fica flutuando, só no ar, porque muitas vezes a gente está bem, outras, outra hora a gente esta, já está meio mal, já está meio assim [U9].

Porque não podia ter preconceito com a gente, não é? A cidade aonde a gente mora, tem muito preconceito com a gente. Não tratam a gente bem, chamam a gente de louco, mas todo mundo tem um pouco de loucura. [U10].

Os usuários, quando tem algum evento do município, alguma coisa desse tipo, eles estão também apresentando as oficinas, apresentando os trabalhos, se apresentando também. Eu acho que é bem assim, firme, a participação deles dentro da sociedade, nas reunióes nos fóruns. [...] Eles estão bastante comprometidos [T6].

$\mathrm{Na}$ fala transcrita a seguir, o usuário relata a experiência de se contrapor e, ao trazer ideias que se chocam com aquelas hegemônicas, seja no espaço da instituição, seja no espaço da sociedade, as resistências se colocam naturalmente. O usuário relata a percepção de atitudes limitadoras, por parte da equipe, em relação a seus posicionamentos, compreende as restrições colocadas pela instituição, porém não interrompe processos de pensamento ede diferenciação, reafirmando seus posicionamentos, mesmo na situação de excluído.

No diário de campo, registro dessa situação, observada in loco pelos observadores, comprovam-se restriçoóes a esse usuário em particular, em dados momentos, justamente pela sua iniciativa de se contrapor ao determinado ou de 
criar outra possibilidade para o que já está estabelecido. Essas resistências, mesmo partindo de singularidades, aparentemente isoladas no contexto institucional, provocam mobilidade e desacomodam, trazendo outras perspectivas de relação. Os trabalhadores são provocados pelos usuários a assumirem posição e perceberem equívocos da prática diária. Os poderes institucionais também ganham visibilidade frente à resistência criada e podem ser pensados desde sua exteriorização.

( $\mathrm{Na}$ assembleia) Olha, eu tentei falar a verdade e eles me excluíram daquela reuniāo porque eu falo super bem, e eu acho que eu falo aquilo que convém, não é? E muitas das vezes não gostam, porque eu venho colocar algumas coisas [...] é as coisas que estão existindo, as coisas que não estão bem e eles não gostam de ouvir [U9].

E se não gostaram da atitude do funcionário, eu acho assim muito bom, porque eles colocam para fora, que às vezes eles ficam, falam dos funcionários, não sei o que, me tratam mal, eles vêm ali, eles cansam de falar, para eles é muito bom, para nós também, pra gente procurar ver o que estava errado, procurar acertar [T12].

Cada profissional tem o seu jeito de trabalhar. Então a gente, às vezes fica um pouco meio na deficiência, um pouco atende a grande demanda que o CAPS II recebe [...] vira e mexe e a gente está com conflito, às vezes chegam usuários que não são atendidos e aí cria um clima, um mal-estar, vai na secretaria de saúde, porque não foi bem atendido [T13].

Mas sabemos que muitas vezes as pessoas que são escolhidas para administrar, até pessoas que não questionam muito. [...] Enfim, incomoda, e tem gente que não gosta de ser incomodada, então eu penso que nesse sentido houve uma centralização de poder [T3].

Há, por parte das instituições, na sociedade capitalista, segundo Guattari (2011), uma tentativa de eliminação da criação, do pensamento dissidente e da produção desejante como forma de boicote à singularização e à promoção de subjetividades de ordem capitalísticas. O autor se refere a essas subjetividades como as produzidas pelas máquinas em série e impessoais, que se relacionam ao consumo de massa e à produção de modelos para a vida nessa sociedade.

A constituição dos poderes que permeiam essas instituições também interfere de forma a impor e estabelecer formas de estar nas instituições sociais, incluindo as que se propõem a produzir saúde, para a manutenção de controle e de garantias de um enquadramento social absoluto.

Nas instituiçôes de atenção psicossocial, a possibilidade de criação e de manifestação de pensamento dissidente está colocada ao lado de aspectos reducionistas e limitadores desses processos por meio de esquemas institucionais e profissionais. Nas falas a seguir é possível identificar tais posições: 
Nós temos que dar o melhor para o CAPS, por causa que eles exigem de nós, tinha que ter uma oficina boa, cada um escolhesse o que se adapta a fazer, não eles escolherem, 'ó, tu vai fazer e pronto, se não tu vai ser excluído daqui' [U9].

Como é que eu vou te explicar, uns dizem uma coisa, às vezes vem um funcionário e diz uma coisa, lá vem outro e diz outra, [...] outro vem e diz 'tem que respeitar as regras', e aí cria aquela coisa assim, sabe, que a gente fica sem saber o que fazer, ao mesmo tempo querendo fazer o que o coração manda, mas muitas vezes não é assim, que a gente também tem regras com eles assim [T15].

Sobre o PTS, é decidido através da terapeuta ocupacional [...] que ela tem lá o relatório, os horários de todos eles [...] eu sei quando eu chego, encontro já eles aqui, mas quem dá os dias certinhos pra eles virem aqui é ela [T11].

Através das observações registradas no diário de campo, é possível constatar atitudes de submissão da iniciativa dos usuários no sentido de expressar pensamento autônomo quanto à condução de propostas terapêuticas na instituição. Uma das profissionais interrompe de forma autoritária essas manifestações, desconsiderando tanto a história de institucionalização dessas pessoas, que não dispunham da possibilidade de ter voz, como o fato de essa expressão de ideias constituir-se como um exercício de subjetivação singular, de crítica à situação vivenciada. $\mathrm{O}$ usuário constitui um modo de fuga em relação ao lugar de invisibilidade no qual a relação de atenção psiquiátrica o coloca. Cria, assim, uma perspectiva de ruptura com a instituição de relações de dependência, de tutela e de passividade, sendo estas estereotipias da relação médico-paciente.

Reclamam, que a profissional $\mathrm{X}$ há tempos não os atende, eles sentem falta da profissional X. Entre essas queixas, a profissional $\mathrm{Y}$ tentou interromper várias vezes, argumentando que não é bem assim, que a profissional $\mathrm{X}$ atende sempre que eles precisam. Pede que eles parem de reclamar [DC 1- 27/07/11].

Tendo o movimento da reforma psiquiátrica como marco político, e o modo psicossocial de cuidar como modelo operativo para romper com lugares de invisibilidade em que a loucura foi colocada na sociedade capitalista e no mundo contemporâneo, as fissuras criadas nesses cenários são investimentos complexos que demandam rupturas de ordem institucional, do campo dos saberes instituídos e dos processos de subjetivação de profissionais e usuários nele implicados.

A singularidade, segundo Pelbart (2003), pode ser do indivíduo, de grupos, de classes, enfim, de qualquer um que produza territórios subjetivos, 
recusando-se à submissão aos poderes constituídos e a superando normas, rotinas e protocolos em sua vida cotidiana.

O contexto histórico produz modos de subjetivação nos profissionais, pelas práticas, saberes e discursos de sua formação, e estabelece determinadas implicações no tecido social no qual eles atuam.

Segundo Rey (2003), a tendência ao enquadramento, à supressão da singularização está se institucionalizando mesmo em espaços e instituições que pretendem produzir pensamento, ciência, saúde, educação, entre outras, como as instituições de ensino e formação. Mesmo os serviços de saúde que propõem reformar suas proposições e práticas de relação com a sociedade podem institucionalizar-se, suprimindo a singularização.

$\mathrm{O}$ modo psicossocial de cuidar apresenta proposições desafiadoras, entre as quais a mudança de concepção de seu objeto, que, ao se descentrar da doença, passa a enfocar o indivíduo em sua singularidade, assim como sua família e seu entorno social. Segundo Costa-Rosa (2006), o reposicionamento do indivíduo em relação ao seu projeto de vida ocupa o lugar da supressão simples da sintomatologia nesse modo de cuidar.

A amplitude da proposta de atenção psicossocial e os limites dos profissionais com formação tradicional nas áreas da saúde podem ser entendidos como aspectos que dificultam as ações. O serviço de saúde mental, mesmo tendo nascido de uma proposta inovadora e reformista, sendo este mesmo singular entre tantas que se propuseram à mesma finalidade, ainda precisa encontrar lugar e afirmarse em sua diferença na rede de saúde e na sociedade de forma geral.

Desnaturalizar o modo de estar no mundo, segundo a perspectiva de condutas, de modos de relação que respondam às demandas da sociedade, por unificação, padronização e disciplina, é entendido como um desafio para os CAPS. Estes se colocam disponíveis para a criação de outras relações, forjando espaços de rupturas com os processos de subjetivação capitalísticas e se posicionando como uma maquinaria potente para fazer circular as singularidades, sendo esta uma prerrogativa de seu ideário de trabalho, dentre cujos objetivos se insere a criação de reapropriação subjetiva e criação de modos de existência.

Por fim, o próprio usuário desses serviços pode se ver, a partir de suas falas, em movimento, em múltiplos sentidos, que podem indicar processos quando se posiciona, questiona, sugere, cria, relaciona, enfim, quando põe a vida a andar, 
em ritmos diversos, em atitudes de maior ou menor autonomia, estabelecendo

conexões e redes que trazem sustentação aos projetos de vida que emergem dessas vivências.

\section{Considerações finais}

A proposta deste artigo, de relacionar os CAPS às possibilidades de produção de subjetividade singularizada, dá-se por esses espaços se constituírem como locais que buscam trabalhar com foco nas pessoas e seus projetos de vida, individuais e coletivos, de forma a construir novos modos de existência e novas formas de viver e conviver com a experiência da loucura.

Entendendo os processos de singularização subjetiva como formas de reapropriação de modos próprios de sentir, pensar e viver a vida, partindo de referenciais próprios e disparando acontecimentos, mesmo que pequenos em seu território existencial, observa-se a possibilidade de esses movimentos estarem ocorrendo e sendo mobilizados no espaço do CAPS. Esse fato possibilita concretizar o propósito de trabalhar para movimentos individuais e coletivos de diferenciação, de criação, de resistência e de heterogeneidade.

Ao longo desta análise, encontramos aspectos importantes nas dinâmicas de trabalho e nos modos de relação que se estabelecem nos serviços de atenção psicossocial, que se posicionam de forma a resistir às iniciativas de normalização, adaptação e assujeitamento individual e coletivo. Entre essas práticas, encontramse a opção por uma clínica produtora e agenciadora de novas possibilidades de reconstrução de projetos de vida, direcionando-se a aspectos individuais e coletivos, na medida em que propõem à sociedade outras formas de conviver com a loucura. A clínica extrapola a expectativa da simples remissão sintomatológica, apontando avanços ao transpor o caráter individualizante, configurando-se em uma ação política.

Os espaços para pensar, criar soluções próprias e inovadoras para os problemas, conflitos e dificuldades da vida cotidiana estão mobilizando os usuários e trabalhadores desse serviço para enfocar o desenvolvimento de múltiplos recursos individuais, coletivos e sociais para um modo singular de viver em sociedade, com respeito às diferenças, desejos, modos de relação e de concepção de mundo. As diferentes oficinas e assembleias configuram-se em espaços potentes para esses acontecimentos. 
Esses espaços foram identificados enquanto potentes instrumentos para os processos de subjetivação e singularização, com os recursos da escuta qualificada, da clínica ampliada e oficinas terapêuticas, que desencadeiam movimentos, processos criativos, relações interpessoais e intervenções na comunidade. Os atravessamentos oportunizados no serviço pelas múltiplas experiências constituem a heterogeneidade necessária à produção de subjetividades singulares entre os atores, de processos desencadeados pela atenção psicossocial.

As dificuldades inerentes a todo o processo de contraposição ao modo hegemônico de desenvolver o cuidado nos serviços de saúde estão presentes nas falas e nas observações realizadas no serviço estudado. Colocam-se como entraves, retrocessos e limitaçôes para o enfrentamento do modo tradicional de cuidar e entender o sofrimento psíquico, considerando que essas mudanças demandam a reinvenção de saberes e práticas nesse campo, com implicações teóricas, técnicas, éticas e políticas. Entre as dificuldades observadas, encontram-se as relaçôes hierárquicas, os procedimentos técnicos imbuídos de caráter controlador, disciplinador, tutelar e a presença de saber-poder no cotidiano do serviço.

Os centros de atenção psicossocial assumem como objetivo primeiro na rede de saúde a responsabilidade com o cuidado clínico ou o tratamento do sofrimento psíquico. Entendem, contudo, que a integralidade e complexidade da pessoa não se limitam à sintomatologia referida, mas são atravessadas por agenciamentos diversos, de ordens sociais, institucionais, entre outras. Impõem-se perspectivas diversas para sua atuação e ampliação de responsabilidade para com aspectos subjetivos da vida das pessoas em acompanhamento nesses serviços.

O estudo aponta para perspectivas de produção de subjetivação no contexto da atenção psicossocial, pelos movimentos, interferências, inovações, experiências e encontros, que se efetivam pela ação cotidiana de usuários e trabalhadores. Podemos, então, associá-los a processos de subjetividade singularizada quando desestabilizam as formas determinadas e instituídas e deixam emergir as multiplicidades existentes no coletivo, nas conexões e nas criações possibilitadas nos serviços de CAPS, constituindo-se em linhas de força que revelam a potência subjetiva desses espaços.

Concluímos, assim, que a atenção psicossocial produz resistências, variabilidade e modos singulares de vida individual e coletiva, movimentos presentes na perspectiva da reforma psiquiátrica brasileira. Os serviços de saúde mental pressupõem uma clínica com o aspecto ético e político, com foco 
na produção de subjetivação dos atores envolvidos nesses serviços, onde as práticas de cuidado se configuram potentes para transformações, criando outras possibilidades de intervençôes, rompendo com modos hegemônicos e seriais de cuidado. Suscitam-se, assim, processos singulares, que operam para a criação de territórios existenciais, construindo novas posturas epistemológicas e de relaçôes com a experiência da loucura. ${ }^{2}$

\section{Referências}

AMARANTE, P. O homem e a Serpente: Outras Histórias para a Loucura e a Psiquiatria. Rio de Janeiro: Ed. Fiocruz, 1996. 141p.

BRASIL. Ministério da Saúde. Secretária de Atenção à Saúde. DAPE. Coordenação Geral de Saúde Mental. Reforma Psiquiátrica e Politica de Saúde Mental no Brasil. Documento apresentado à Conferência Regional de Reforma dos serviços de saúde mental: 15 anos depois de Caracas. OPAS. Brasília, novembro de 2005. Disponível em: <http://bvsms. saude.gov.br/bvs/publicacoes/Relatorio15_anos_Caracas.pdf>. Acesso em: 26 mar. 2017

COSTA-ROSA, A. O modo psicossocial: Um paradigma das práticas substitutivas ao modo asilar. In: AMARANTE, P. (org.). Ensaios - Subjetividade, saúde mental, sociedade. Rio de Janeiro: Ed. Fiocruz, 2006. p. 141-168.

DELEUZE, G. O abecedário de Gilles Deleuze. 1988. Transcrição integral do vídeo para fins exclusivamente didáticos. Disponível em: <www.docstoc.com/search/gilles-deleuze>. Acesso em: 08/06/2012.

DELEUZE, G.; GUATTARI, F. Mil platôs: Capitalismo e esquizofrenia. v. 3. São Paulo: Ed. 34, 1996. 144p.

FOUCAUlT, M. Microfísica do Poder. Rio de Janeiro: Ed. Graal Ltda, 1992. 295p.

GUATTARI, F.; ROLNIK, S. Micropolitica: cartografias do desejo. 11. ed. Petrópolis: Ed. Vozes, 2011. 327p.

GUBA, E. G; LINCOLN, Y. S. Effective Evaluation. San Francisco: Jossey-Bass Publishers, 1985. 423p.

Fourth Generation Evaluation. Newbury Park: Sage Publications, 1989. 294p.

HORKHEIMER, M. O eclipse da razão. São Paulo: Ed. Centauro, 2007. 176p.

KANTORSKI, L. P. Projeto de Pesquisa de Avaliação dos Centros de Atenção Psicossocial da regiāo Sul do Brasil (CAPSUL). Pelotas, 2006. Disponível em: <http://www.ufpel.edu.br/ feo/capsul.php>. Acesso em: 24/10/2011.

KANTORSKI. L. P. et al. Contribuições do Estudo de Avaliação dos Centros de Atenção Psicossocial da Região Sul Do Brasil. Cadernos Brasileiros de Saúde Mental, Florianópolis, v. 1, n.1, p.1-9, 2009. 
PELBART, P. P. Vida capital: Ensaios de biopolíitica. São Paulo: Ed. Iluminuras, 2003. 252p. REY, F. G. Sujeito e subjetividade. São Paulo: Ed.Thomsom, 2003. 290p.

SOARES, L. B.; MIRANDA, L. L. Produzir subjetividades: o que significa? Estudos e Pesquisa em Psicologia, Rio de Janeiro, v. 9, n 2, p.408-424. 2009.

WETZEL, C. Avaliação de serviços de saúde mental: a construção de um processo participativo. 2005. 290 f. Tese (Doutorado). Escola de Enfermagem de Ribeirão Preto. Universidade de São Paulo, Ribeirão Preto. 2005.

\section{Notas}

${ }^{1}$ Este artigo é um resultado parcial da dissertação de mestrado intitulada "A produção de subjetividade no modelo de atenção psicossocial", defendida no Programa de Pós-graduação da Faculdade de Enfermagem da UFPEL.

${ }^{2}$ C.T.L. Argiles trabalhou na concepção, delinemento do projeto, análise, interpretação dos dados e redação do artigo. L.P. Kantorski trabalhou na concepção e coordenação do projeto de pesquisa, delineamento, interpretação dos dados, orientação e revisão crítica do artigo. J.Q. Wilrich trabalhou na concepção e elaboração do projeto de pesquisa, coleta de dados e revisão do artigo. V.C.C. Coimbra trabalhou na concepção e elaboração do projeto de pesquisa e revisão do artigo. 
Singularization processes in the psychosocial mode

The article aims to report the possibilities of production of singularized subjectivity or singularization processes in the service of Alegrete-RS, Brazil, considering the need to identify the proximities and distances of proposed practices and goals since the psychiatric reform related to this service. A case study was conducted whose data was obtained from semi-structured interviews with 11 users and 21 workers, and also from participant observation which totalized 253 hours. Aspects of innovation in practices and dynamics with the purpose to promote thinking, creativity and resistance were found potentiating the subjectivity and processes of singularization of the people involved in the psychosocial attention. The relations built lead to the development of multiple individual, collective and social resources, to a particular way to live in society, respecting differences, desires, kinds of relationship and conception of the world.

Keywords: mental health; psychosocial attention; subjectivity; singularization processes. 